\title{
Brucella pinnipedialis in lungworms Parafilaroides sp. and Pacific harbor seals Phoca vitulina richardsi: proposed pathogenesis
}

\author{
Jack Rhyan ${ }^{1, *}$, Mike Garner ${ }^{2}$, Terry Spraker ${ }^{3}$, Dyanna Lambourn $^{4}$, \\ Norman Cheville ${ }^{5}$ \\ ${ }^{1}$ United States Department of Agriculture, National Wildlife Research Center, Fort Collins, CO 80521, USA \\ ${ }^{2}$ Northwest ZooPath, Monroe, WA 98272, USA \\ ${ }^{3}$ Colorado State University Diagnostic Laboratory, College of Veterinary Medicine and Biomedical Sciences, \\ Colorado State University, Fort Collins, CO 80526, USA \\ ${ }^{4}$ Washington Department of Fish and Wildlife, Marine Mammal Investigations, Lakewood, WA 98498, USA \\ ${ }^{5}$ Department of Veterinary Pathology, College of Veterinary Medicine, Iowa State University, Ames, IA 50010, USA
}

\begin{abstract}
Brucella spp. were first isolated from marine mammals in 1994 and since have been described in numerous pinniped and cetacean species with nearly global distribution. Microscopic, electron microscopic, or culture results have shown lungworms in harbor seals to be infected with brucellae, suggesting that the lungworms may serve a role in this infection. In this study, we reviewed archived and more recent case material from 5 Pacific harbor seals from Washington State (USA) with evidence of $B$. pinnipedialis infection in the lungworm Parafilaroides sp. Twenty-two sections of lung containing approximately 220 Parafilaroides sp., stained with an immunohistochemical technique using antibody to $B$. abortus, showed approximately $80(36 \%)$ infected nematodes. A few brucellae were also present in lung parenchyma in proximity to nematodes. Infection was present in the first- and fourth-stage larvae in the seal lung and intestines, as well as in the male and female reproductive organs of adult nematodes. Infected sperm deposits in the nematode uterus were suggestive of venereal transmission between lungworms. Massive infection of some degenerate adult lungworms and evidence of degeneration of some developing larvae in utero were observed. Based on these observations, we suggest that Parafilaroides sp., rather than the Pacific harbor seal Phoca vitulina richardsi, is the preferred host of $B$. pinnipedialis infection.
\end{abstract}

KEY WORDS: Brucella $\cdot$ B. pinnipedialis $\cdot$ Harbor seals $\cdot$ Lungworm $\cdot$ Parafilaroides $\cdot$ Pathogenesis · Phoca vitulina $\cdot$ Immunohistochemistry

\section{INTRODUCTION}

In 1994, novel brucellae were reported from harbor seals Phoca vitulina, harbor porpoises Phocoena phocoena, a common dolphin Delphinus delphis (Ross et al. 1994), and an aborted bottlenose dolphin Tursiops truncatus (Ewalt et al. 1994, Miller et al. 1999). Since then, Brucella spp. have been isolated from a wide spectrum of marine mammal species with nearly global distribution (Nymo et al. 2011, Hernández-

${ }^{*}$ Corresponding author: jack.c.rhyan@aphis.usda.gov
Mora et al. 2013). According to current nomenclature, isolates from cetaceans are referred to as Brucella ceti, and B. pinnipedialis is used for isolates from pinnipeds (Foster et al. 2007). Recent genomic work has disclosed 5 sequence types (STs) that fall into 3 major groupings among the marine isolates (Whatmore et al. 2017). Two STs (24 and 25) correspond with $B$. pinnipedialis isolates, 2 (23 and 26) with isolates from cetaceans, and 1 genotype (ST27) with isolates from bottlenose dolphins, California

(C) M.G., T. S., D. L., N.C. and, outside the USA, the US Government 2018. Open Access under Creative Commons by Attribution Licence. Use, distribution and reproduction are unrestricted. Authors and original publication must be credited.

Publisher: Inter-Research · www.int-res.com 
sea lions Zalophus californianus, and 3 naturally acquired cases in humans (Sohn et al. 2003, McDonald et al. 2006, Whatmore et al. 2017). Experimental infections of marine isolates in sheep and cattle have shown limited pathogenicity, only producing seroconversion in both species and abortion in cattle following intravenous injection (Rhyan et al. 2001, Perrett et al. 2004a). Several lesions have been associated with $B$. ceti infections in cetaceans, including orchitis (Dagleish et al. 2008), meningoencephalitis (González et al. 2002, Hernández-Mora et al. 2008), abscesses, in utero pneumonia (Colegrove et al. 2016), placentitis (González-Barrientos et al. 2010), and abortion (Nymo et al. 2011, Guzmán-Verri et al. 2012). In contrast, minimal lesions have been found in pinnipeds associated with $B$. pinnipedialis infection. Focal areas of pneumonia have been described in harbor seals with Brucella-infected lungworms (Garner et al. 1997), and a single focal area of placentitis, positive for Brucella sp. by immunohistochemistry (IHC), was observed in a northern fur seal Callorhinus ursinus that apparently gave birth to a live pup (Duncan et al. 2014).

In a survey of harbor seals in Washington State, USA, conducted between 1996 and 2004, B. pinnipedialis was isolated from specimens collected from 18 of 102 seals (Lambourn et al. 2013). In 1996, Brucella sp. organisms were demonstrated by IHC and electron microscopy in the intestine and uterus of Parafilaroides sp. lungworms in a harbor seal from Puget Sound (Garner et al. 1997), and subsequently in 2 additional seals from Puget Sound (Rhyan 2000). Later, brucellae were demonstrated by IHC, culture, and/or immuno-electron microscopy in Parafilaroides sp. lungworms in a harp seal Pagophilus groenlandicus (Maratea et al. 2003) and in lungworms in harbor porpoises (Perrett et al. 2004b, Dawson et al. 2008, Jauniaux et al. 2010, Maio et al. 2014).

The species of the $B$. pinnipedialis-infected Parafilaroides in Puget Sound harbor seals is unknown; however, a survey between 2000 and 2006 of harbor seals in San Juan County, Washington, found $P$. gymnurus, an unidentified Parafilaroides, and $P$. gullandae (Lambourn et al. 2013). P. gullandae was recently described from a Pacific harbor seal Phoca vitulina richardsi on the California coast (Dailey 2006). As is the case for many marine mammal parasites, the life cycle of the Parafilaroides spp. found in harbor seals in the Puget Sound area has not been determined. However, the life cycle of $P$. decorus, a similar lungworm which infects California sea lions, was determined by Dailey (1970). Firststage larvae are released from oviparous adult female nematodes in the lung, migrate up the respiratory tract, and are coughed up to exit the sea lion through the mouth or are swallowed and exit in the feces. Those in feces are consumed by coprophagic fish, notably the opaleye Girella nigricans, and perhaps others. The larvae penetrate the fish intestine and go through 2 molts in the intestinal wall or mesenteric fat of the fish. The encysted third-stage larvae are consumed by a sea lion, released, and penetrate the sea lion's intestinal wall. They next migrate to the sea lion's lungs where they progress to the fourth stage of development. The exact path of migration in the sea lion is unknown. In the lung, the nematodes mature to adults (L5), copulate, and produce offspring.

The life cycle of the Parafilaroides spp. in harbor seals is assumed to be similar to that of $P$. decorus utilizing a fish or invertebrate as an intermediate host. Recent work on P. gymnurus in Eastern Atlantic harbor seals $P$. vitulina vitulina suggested 3 fish species as potential intermediate hosts: hooknose Agonus cataphractus, European plaice Pleuronectes platessa, and common dab Limanda limanda (Lehnert et al. 2010, Osinga 2015).

The demonstration of brucellae in marine mammal lungworms has led to speculation that the nematode may serve as a vector of infection between marine mammalian hosts (Garner et al. 1997, Rhyan 2000, Dawson et al. 2008). In this study, we reviewed archived and more recent case material from harbor seals from Washington State to better understand the pathogenesis of this infection.

\section{MATERIALS AND METHODS}

Archived Brucella-IHC stained slides and Brucella-IHC-stained fresh-cut sections from archived, paraffin blocks and fresh case material from a total of 35 Pacific harbor seals (Phoca vitulina richardsi) were examined. The IHC staining technique for Brucella antigen on archived sections has been reported (Garner et al. 1997). Recent $5 \mu \mathrm{m}$ sections were IHC labeled with the same $B$. abortus polyclonal antibody (1:1500 dilution) used previously in a Leica MAX automated immunostainer (Leica Microsystems) using the Leica PowerVision immunostaining system and alkaline phosphatase red chromagen. Sections were counterstained with hematoxylin. Additionally, archived $1 \mu \mathrm{m}$ epoxyembedded sections stained with toluidine blue were re-examined. Archived and recent IHC sections were prepared at the Pathobiology Laboratory, 
National Veterinary Services Laboratories, Ames, Iowa, USA (NVSL); the archived $1 \mu \mathrm{m}$ sections were prepared at the National Animal Disease Center, Ames, Iowa.

Lung sections from 20 harbor seals contained lungworms, and; 5 of these seals had nematodes morphologically consistent with Parafilaroides spp. (Morales \& Helmboldt 1971, Measures 2001, Gardiner \& Poynton 2006) containing Brucella IHCpositive material (seals $1-5$ ). The 5 seals ( 2 females and 3 males) were weaned pups and subadults. Details from seal 1 have been described previously (Garner et al. 1997). Seals 2-4 have also been mentioned in previous reports (seal 1 = WDFW96-13, seal 2 = WDFW97-4, seal 4 = WDFW0104-3 in Lambourn et al. 2013; seal 3 in Rhyan 2000). Seal 5 (WDFW2016-007) died within hours of capture in 2016 and, on necropsy, had severe intestinal and pulmonary parasitism with accompanying pneumonia. Seals 1, 2, 4, and 5 were serologically positive for Brucella spp. (Washington Department of Agriculture Laboratory, Olympia, WA, USA; and NVSL) and culture positive for $B$. pinnipedialis (NVSL). Neither serology nor culture was done on seal 3. Isolates from seals 1 and 2 were not sequenced; isolates from seals 4 and 5 were ST25. In the 4 seals submitted for culture, B. pinnipedialis colonies from lung were too numerous to count (TNTC). Seal 2 also had heavily infected ( $B$ pinnipedialis) thoracic lymph nodes, and seals 2 and 5 had culture-positive feces. Several other tissues, including liver, pancreas, tonsil, spleen, eye, kidney, urinary bladder, ovary, and multiple lymph nodes from 1 or more of the 4 cultured seals had 1 to few colonies. Cultures from lungworms (likely Otostrongylus sp.) obtained from bronchi of seals 4 and 5 also yielded TNTC B. pinnipedialis. Typical histological lesions associated with Brucella spp. infection in cetacean or terrestrial species had not been found in any of these harbor seals on post mortem examination by the referring pathologist.

\section{RESULTS}

Hematoxylin and eosin and IHC-stained sections cut from 14 blocks containing 22 lung specimens from the 5 seals with IHC Brucella-positive lungworms were examined. Approximately 220 nematodes morphologically consistent with Parafilaroides spp. were observed, of which approx. 80 (36\%) were positive for Brucella antigen. Variably sized lung sections from Seals 1 through 5 contained approx.
73, 41, 44, 12, and 50 Parafilaroides spp., respectively, of which approx. 45,44,43, 83, and $4 \%$ were IHC positive for brucellae. Approximate numbers are reported due to the nematodes' tendency to fold or coil in lung tissue and their tendency to occur in clusters of 3 to 5 adults (Morales \& Helmboldt 1971), making it difficult to distinguish separate nematodes. As reported, immuno-gold labeling and Giemsa stained sections demonstrated that IHC-positive particles observed in Parafilaroides spp. were, in fact, small cocco-bacilli morphologically and antigenically consistent with Brucella spp. (Garner et al. 1997, Rhyan 2000).

In harbor seals with IHC-positive Parafilaroides spp. nematodes, $B$. pinnipedialis were present in adult male (Fig. 1A-C) and female (Fig. 1D-F) lungworms and in first- and fourth-stage larvae (Fig. 2A-E) located in the lung parenchyma. Additionally, Brucella-infected first-stage larvae were present in the lumen of the large intestine of seal 2 (Fig. 2C). In adult nematodes, brucellae were present in the uterus, male gonad, and in the lumen of the intestine. In the uterus, organisms were routinely adjacent or attached to the membranes separating the larvae. Brucellae were present around ova, and in some cases were located inside ova and in developing larvae within the nematode uterus (Fig. 1E,F). In $1 \mu \mathrm{m}$ sections, bacterial clusters were present on the uterine lining, on membranes between larvae, and occasionally adherent to in utero larvae. Degenerative changes were observed in a few of the larvae surrounded by bacteria in heavily infected nematode uteri (Fig. 2A). In the adult nematode intestine, brucellae, when present, varied from few organisms to extensive colonization occupying the entire intestinal lumen (Fig. 1D). In fourth-stage larvae, which lack a developed reproductive tract, brucellae were located in the lumen of the intestine (Fig. 2D,E).

In histological lung sections of seals 1 and 2, there were randomly scattered foci of suppurative pneumonia. These foci were often associated with viable or dead lungworms, some of which were IHC positive for Brucella sp. Some pneumonic areas had large numbers of intra- and extracellular brucellae present in leukocytes, and some contained nematode larvae or remnants of degenerate nematodes (Fig. 2F). Many pneumonic areas lacked brucellae, and some contained IHC-negative degenerating nematodes. Lung sections of seals 3 and 4 had only a few Brucella-infected nematodes, and lacked areas of pneumonia. Lung sections from seal 5 had numerous Parafilaroides sp. and several areas of focal pneumonia devoid of IHC-positive staining. The sections 


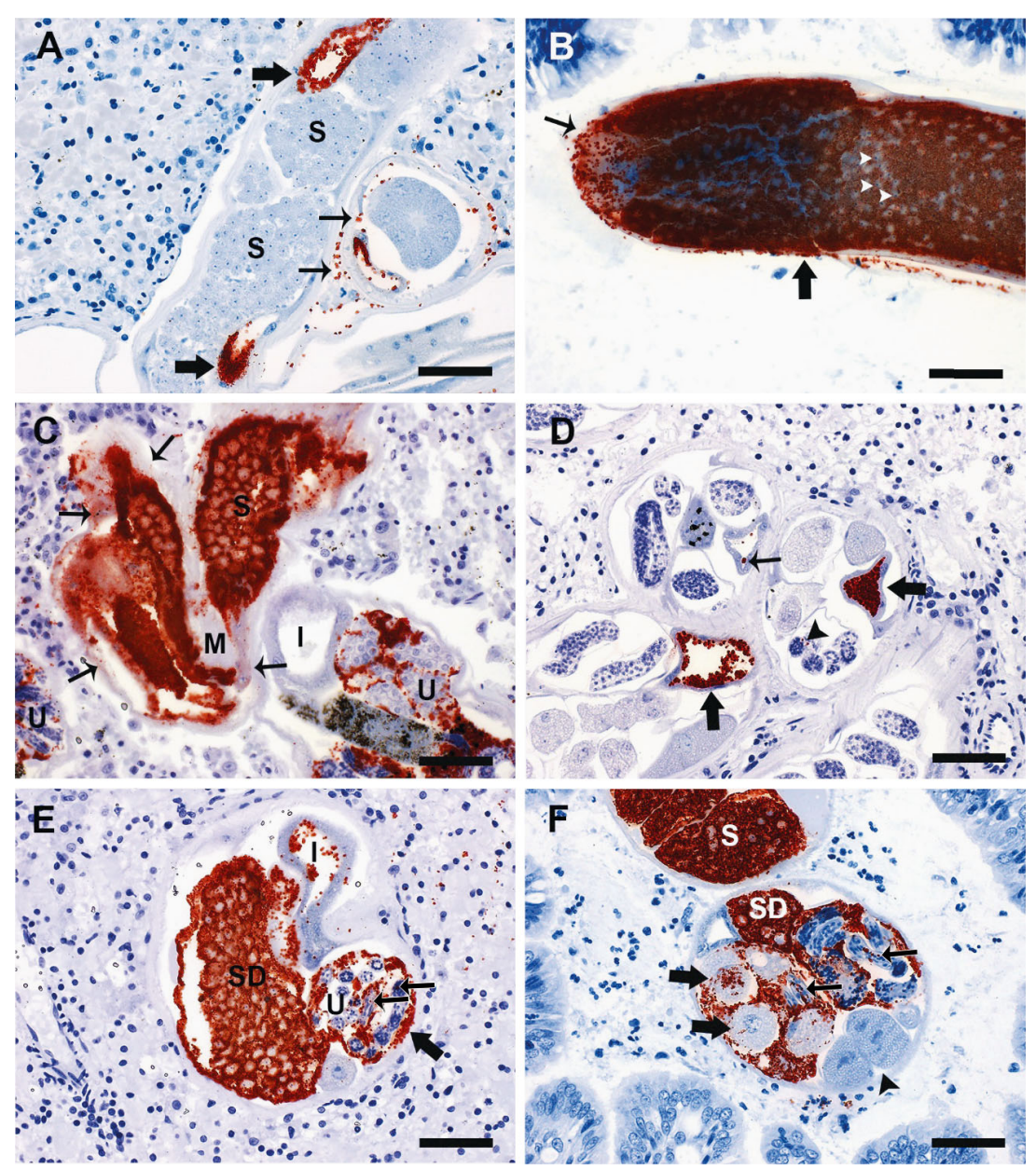

Fig. 1. Adult Parafilaroides sp. with Brucella pinnipedialis infection (immunohistochemical stain; all scale bars $=50 \mu \mathrm{m}$. (A) Male nematode with red-labeled brucellae in intestine (thick arrows) and scattered in the adjacent nematode section (thin arrows). Note uninfected gonad with large number of spermatozoa (S). (B) Male nematode in seal bronchiole. Note red labeling of individual (thin arrow) and clumped (thick arrow) B. pinnipedialis and discernable spermatozoa (white arrowheads). (C) Massively B. pinnipedialis-infected, degenerating, male nematode (M). Note degeneration of cuticle of parasite (thin arrows) and large clumps of red-labeled brucellae and spermatozoa (S) within the degenerate nematode. Also note adjacent viable-appearing nematode sections with red-labeled brucellae in uterus (U) but not intestine (I). (D) Female nematode sections with scant (thin arrow) to marked (thick arrows) B. pinnipedialis colonization of the intestine and 2 organisms on cross section of developing larva (arrowhead). (E) Section of female Parafilaroides sp. (thick arrow). Note brucellae in intestine (I), surrounding and inside developing larvae in uterus (thin arrows), and colonizing large sperm deposit (SD) in uterus (U). (F) Female Parafilaroides sp. with B. pinnipedialis-infected, degenerating ova (thick arrows) and normal-appearing, uninfected, ova (arrowhead). Also note developing, infected larvae (thin arrows) and sperm deposit (SD).

Nematode section above has positive sperm (S)

appeared viable, not showing degenerative changes. Some degenerating nematodes, however, were massively colonized by brucellae (Fig. 1C). Male gonads of the nematodes were especially prone to heavy $B$. pinnipedialis colonization (Fig. 1B,C).

First-stage larvae were often present in airways or connective tissue of interlobular septae, and were occasionally found in a loose linear arrangement in septae. When infected with $B$. pinnipedialis, they were sometimes located along one of these tracts, with free brucellae scattered between the larvae (Fig. 2B). Brucella organisms were not generally present in the lung parenchyma remote from adult or larval nematodes, and only a few brucellae were present in lung tissue surrounding viable nematodes. Infected male and female nematodes were present in close proximity to each other, often in the same parasitic cluster, and the uterus of some female nematodes contained Brucella-infected semen deposits (Fig. 1E,F). Nematode clusters, if Brucella positive, usually contained more than 1 positive adult.

In lung sections from 3 seals with no IHC-positive lungworms, 1 seal had IHC-positive material in a few macrophages in airways, and sections from 2 additional seals had IHC-positive Brucella antigen in granulomas associated with degenerating nematodes. Thoracic lymph node sections from seal 2, which were positive on culture for B. pinnipedialis, had mild to moderate lymphofollicular hyperplasia but no lymphadenitis. On IHC, 3 macrophages located in the medulla contained clusters of posi-

contained 2 B. pinnipedialis-positive Parafilaroides sp. without associated pneumonia.

Although many adult nematodes were moderately to markedly colonized with $B$. pinnipedialis in their intestine or reproductive organs, they tive-staining brucellae in the cytoplasm. Lung sections from seal 5 had nematodes morphologically consistent with Otostrongylus circumlitus in the bronchioles. These nematodes were negative for brucellar antigen on IHC. 


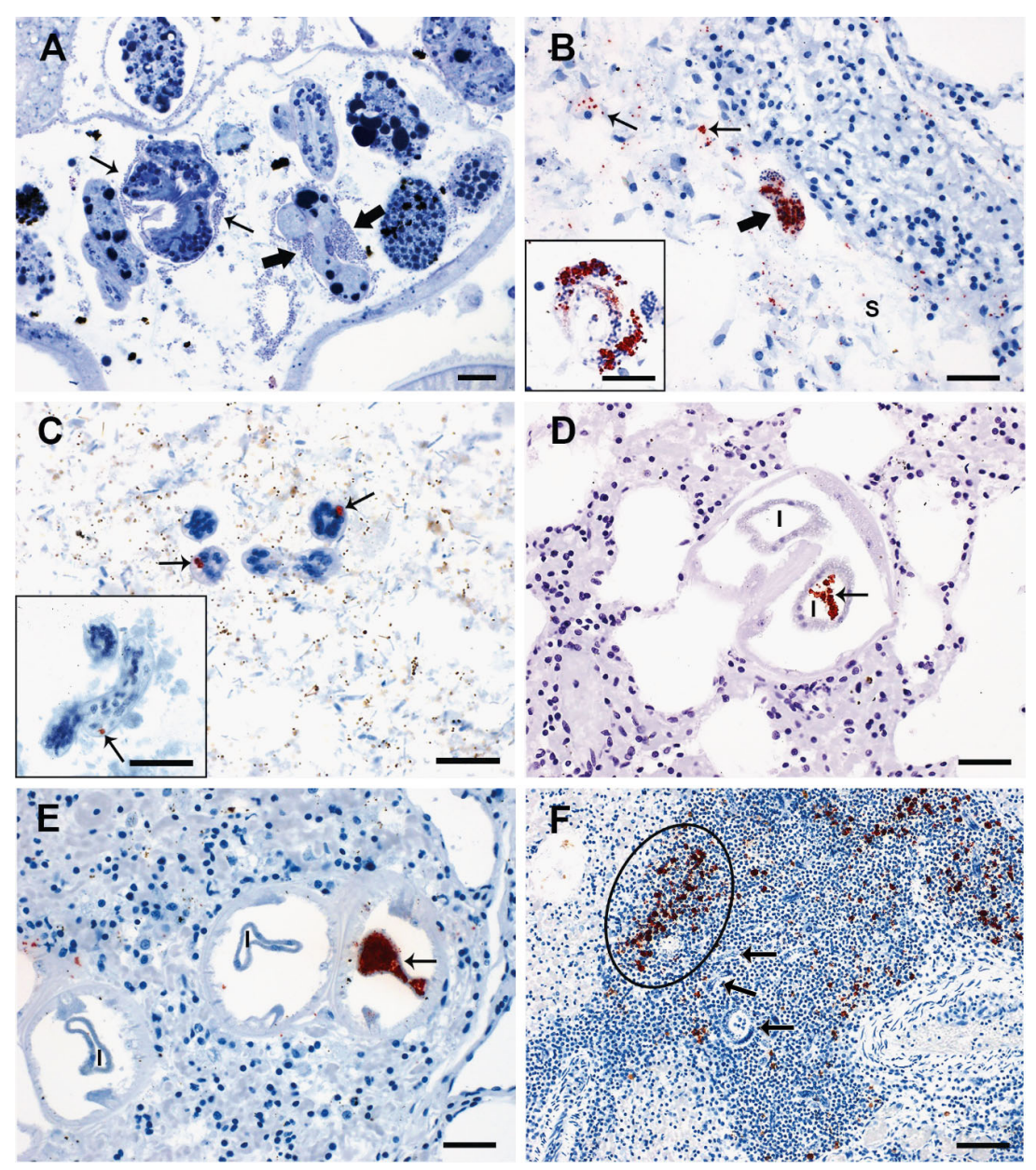

Fig. 2. Larval Parafilaroides sp. and Brucella pinnipedialis infection. (A) $1 \mu \mathrm{m}$, epoxyembedded section of nematode uterus. Note bacteria surrounding membrane around viable-appearing larva (thin arrows), and marked bacterial colonization around degenerating larva (thick arrows). Toluidine blue; scale bar $=20 \mu \mathrm{m}$. (B) $B$. pinnipedialis-infected first-stage larva (thick arrow) in interlobular septum (S) of seal lung. Note scattered brucellae (thin arrows) in proximity to larva. Inset shows another infected first-stage larval Parafilaroides sp. Immunohistochemical stain (IHC); scale bars $=25 \mu \mathrm{m}$. (C) Cross sections through a coiled first-stage larva in seal large intestine with few labeled brucellae (thin arrows). Inset has section through another larva in seal large intestine with 1 organism (thin arrow). IHC; scale bars $=20 \mu \mathrm{m}$. (D) Fourth-stage larva in seal lung with few labeled brucellae (arrow) in 1 segment of intestine (I) but not adjacent segment (I). IHC; scale bar = $50 \mu \mathrm{m}$. (E) Fourth-stage larval Parafilaroides sp. in seal lung with marked colonization in 1 segment of intestine (arrow). Intestine is negative in 2 other segments (I). $\mathrm{IHC}_{i}$ scale bar $=50 \mu \mathrm{m}$. (F) Harbor seal lung with focal area of pneumonia. Note lungworm larvae (arrows) and red-labeled, intra- and extra-cellular brucellae in inflammatory cells (concentrated in oval). IHC; scale bar $=50 \mu \mathrm{m}$

Parafilaroides sp. and its host, Phoca vitulina. This proposed pathogenesis scenario is founded on the reported nematode life cycle (Dailey 1970, Measures 2001, Lehnert et al. 2010). The infected adult nematode resides in the seal lung, reproducing live first-stage larvae, some of which are B. pinnipedialisinfected in utero. Those infected larvae may die and degenerate in the uterus or may be born infected and carry the infection as they migrate out of the lungs. Also, the infected adult nematodes shed the brucellae at parturition, in their excrement, and upon death, the latter potentially caused by massive $B$. pinnipedialis infection. These Brucella organisms, both free and inside first-stage lungworm larvae, are coughed up and swallowed, infecting the seal's feces. The infected seal feces is then consumed by coprophagic fish or other marine organisms including likely intermediate hosts of Parafilaroides sp. Young weanling seals consume the infected fish or other marine organisms, which may result in direct transmission of $B$. pinnipedialis to the seals. Alternatively, the seal may consume the intermediate host of the Parafilaroides nematode containing Brucella-infected thirdstage larvae. These larvae would then penetrate the seal's intestine and migrate to the seal's lungs, likely shedding brucellae as they migrate. These 2 scenarios, i.e. (1) direct transmission through the consumption of Brucella-contaminated aquatic organisms and (2) the migration of Brucella-infected Parafilaroides sp. larvae to the seal lung, may account in part for the

\section{DISCUSSION}

Based on examination and review of this case material, and in consideration of culture results and the lack of Brucella-associated lesions in harbor seals, we propose the following hypothetical pathogenesis of $B$. pinnipedialis infection in the nematode small numbers of $B$. pinnipedialis often cultured from a variety of non-pulmonary seal tissues. In the lung, however, the nematodes attain sexual maturity and begin to reproduce, resulting in marked amplification of the $B$. pinnipedialis infection. Adult males with infected gonads transmit infection to females via infected semen, and adult females give birth to 
infected larvae, completing the life cycle of the nematode and infection cycle of the bacterium.

We propose that the nematode Parafilaroides sp. is the preferred host of the pathogen $B$. pinnipedialis. This bacterium behaves in the nematode as most Brucella spp. do in their preferred mammalian hosts: it migrates to the gonads, proliferates, and is shed at parturition, likely producing the equivalent of abortions and infected offspring. In contrast, no abortions, gonadal infections, or lesions other than the focal nematode-related pneumonia, have been found associated with $B$. pinnipedialis in harbor seals. The focal pneumonia is caused by degenerating Parafilaroides sp., which if infected by $B$. pinnipedialis results in massive numbers of brucellae in leukocytes in the local inflammatory cell response. Additionally, a localized inflammatory response would be expected following the parturition of an infected nematode releasing large numbers of brucellae and larvae, some of which may be degenerate. We propose that the seal serves the $B$. pinnipedialis infection by providing a temperature-controlled site for the concentration of infected and uninfected lungworms. The seal's lungs are somewhat equivalent to a feedground in the greater Yellowstone area, where elk Cervus canadensis congregate for food and, in so doing, transmit $B$. abortus infection to uninfected elk via abortion and post parturient shedding (Cheville et al. 1998).

Several recent findings support the host role of the nematode in this infection. The highest prevalence of B. pinnipedialis infection in harbor seals, as determined by culture and serology, occurs after weaning and tends to decline with age (Lambourn et al. 2013, Kershaw et al. 2017). Results of a serologic survey of harbor seals in Alaska indicated seroconversion occurring between 4 and 8 mo of age (Hoover-Miller et al. 2017). This corresponds to the time when seals become parasitized with lungworms as they begin to feed on prey after a post-weaning fast (Muelbert \& Bowen 1993, Ulrich et al. 2016). With age, both lungworm infection and $B$. pinnipedialis infection decreases. Three surveys involving the culture of tissues from harbor seals found the lung to be the most frequently infected tissue, and it had the highest number of colony counts of any organ sampled (Lambourn et al. 2013, Kershaw et al. 2017, Kroese et al. 2018). Lung and thoracic lymph nodes are not favored sites of predilection for terrestrial mammalian Brucella spp. except in fetuses and neonates from in utero inhalation of infected amniotic fluid. Also, the culture of some lungworms from harbor seals has yielded large numbers of brucellae (Lam- bourn et al. 2013). It should be noted that similar agerelated serologic findings in other seal species have been reported without apparent lungworm infection (Nymo et al. 2013).

In vitro studies have suggested that pinnipeds may not serve as definitive hosts for $B$. pinnipedialis. A recent experiment found that alveolar macrophages obtained from hooded seals Cystophora cristata could be infected in vitro with 2 strains of $B$. ceti and 2 of $B$. pinnipedialis, including the strain isolated from hooded seals (Larsen et al. 2013). However, the marine mammal strains did not multiply intracellularly and were eliminated from the macrophages by $48 \mathrm{~h}$ post infection. This was in contrast to $B$. suis that established persistent infection in the hooded seal alveolar macrophages. Harbor seal B. pinnipedialis also were quickly eliminated from hooded seal primary epithelial cells (Larsen et al. 2016) and peripheral blood mononuclear cells (Nymo et al. 2016). However, in mononuclear cells from Atlantic cod Gadus morhua, B. pinnipedialis survived for $48 \mathrm{~h}$ without a major reduction in bacterial counts. The organism also produced disseminated infection persisting for $28 \mathrm{~d}$ without producing lesions in experimentally infected Atlantic cod (Nymo et al. 2016). These studies suggest a role for fish as potential hosts and/or vectors, not only for lungworms but also their associated B. pinnipedialis infection.

Many details in our proposed scenario for B. pinnipedialis pathogenesis in harbor seals need to be determined or confirmed through more observation and experimental work. Experimental infection and pathogenesis studies should be conducted in nematodes both in in vitro cultured larvae and following the infection through the third larval stage in fish. The most interesting question is whether or not the nematode can carry the infection through its developmental stages in the intermediate host. This will require identifying the intermediate host of the harbor seal Parafilaroides or determining if the Parafilaroides decorus-California sea lion-opaleye model will suffice to test the theory. Another question involves the portal(s) of entry of the organism into the nematode. Our findings indicate that some of the ova and in utero developing larvae can become infected. The presence of heavily infected semen deposits in the uterus of the female nematodes suggests the likelihood of venereal transmission. The brucellae may gain entrance to the developing firststage larvae in utero or after birth via the buccal cavity (Dailey 1970). The brucellae may be transferred to the second- and third-stage larvae in the intermediate or transport hosts (fish) and then to other seals. In addition, $B$. pinnipedialis colonization of the gut of fourth- 
stage larvae and adult nematodes in the seal lung may suggest that infection can be contracted by the larvae's ingestion of brucellae prior to arrival in the lung or in the Brucella-contaminated lung environment. Also, the course of infection in the nematode needs confirmation. How does infection move from the nematode intestine to the gonad and at what point does overwhelming infection result in nematode mortality? The potential role of the larger lungworm Otostrongylus circumlitis in B. pinnipedialis infection needs investigation in light of positive culture results (Lambourn et al. 2013). Continued surveillance is needed to determine if $B$. pinnipedialis produces as yet undetected lesions in harbor seals, and what other aquatic organisms are involved in the ecology of this infection. Obviously, the pathogenesis of marine brucellae in other seal species could be very different.

A situation that is somewhat similar to the proposed B. pinnipedialis infection of lungworms is that of Wolbachia spp. infection of Onchocercidae, a family of filarial nematodes. Wolbachia spp. are gramnegative, intracellular organisms in the order Rickettsiales that commonly infect arthropods. In the 1970s they were found in several filarids of humans and animals. The most notable example in animals is that of the canine heartworm Dirofilaria immitis. The bacteria are maintained throughout the life cycle of the nematode, infect lateral hypodermal chords, the nematode uterus, and developing ova and microfilaria (Kramer et al. 2003). Similar to B. pinnipedialis, the bacteria are shed at parturition of the nematode. Unlike the situation in the seal lungworm, Wolbachia spp. are necessary for the reproduction of $D$. immitis and do not cause lesions or degeneration of the nematode. Antibiotic treatment of the $D$. immitis-infected dog results in degeneration of the developing heartworm ova and cessation of microfilaria production. Also, while nearly always present in the adult nematode uterus, Wolbachia spp. are not found in the male testis. Transmission among filarids is considered to be exclusively vertical, and the organisms are considered obligate endosymbionts. Their infection of filarial nematodes is thought to be mutualistic rather than parasitic (Bouchery et al. 2013).

In summary, immunohistopathologic examination of approximately $80 \mathrm{~B}$. pinnipedialis-infected Parafilaroides sp. lungworms in tissue sections of lung from 5 harbor seals suggests that the role of the nematode is not that of the vector but rather that of the host. Over 2 decades after brucellosis was discovered in marine mammals, our knowledge of the pathogenesis and epidemiology of these fascinating infections is still rudimentary.
Acknowledgements. We thank Kristin Wilson, Sharon Lund, Darla Ewalt, Christine Quance, Judy Stasko, and Suelee Robbe-Austerman at the US Department of Agriculture, National Centers for Animal Health, for their excellent laboratory work and review of the manuscript (S. Robbe-Austerman); Madison Funk at Colorado State University (CSU) for her expert help with the figures; Ashley McGrew, parasitologist at CSU, for her review of the manuscript and welcome suggestions; Ro Brown of Histology Consulting Service for slide preparation; and Cathy Minogue of Northwest ZooPath for data retrieval.

\section{LITERATURE CITED}

Bouchery T, Lefoulon E, Karadjian G, Nieguitsila A, Martin C (2013) The symbiotic role of Wolbachia in Onchocercidae and its impact on filariasis. Clin Microbiol Infect 19: 131-140

Cheville NF, McCullough DR, Paulson LR (1998) Brucellosis in the Greater Yellowstone Area. National Research Council, National Academy of Sciences, National Academy Press, Washington, DC

Colegrove KM, Venn-Watson S, Litz J, Kinsel MJ and others (2016) Fetal distress and in utero pneumonia in perinatal dolphins during the Northern Gulf of Mexico unusual mortality event. Dis Aquat Org 119:1-16

Dagleish MP, Barley J, Finlayson J, Reid RJ, Foster G (2008) Brucella ceti associated pathology in the testicle of a harbour porpoise (Phocoena phocoena). J Comp Pathol 139: $54-59$

Dailey MD (1970) The transmission of Parafilaroides decorus (Nematoda: Metastrongyloidea) in the California sea lion (Zalophus californianus). Proc Helminthol Soc Wash 31: 215-222

*Dailey MD (2006) Restoration of Parafilaroides (Dougherty, 1946) (Nematoda: Metastrongyloidea) with description of two new species from pinnipeds of eastern central Pacific. J Parasitol 92:589-594

*Dawson CE, Perrett LL, Stubberfield EJ, Stack JA and others (2008) Isolation and characterization of Brucella from the lungworms of a harbor porpoise (Phocoena phocoena). J Wildl Dis 44:237-246

Duncan CG, Tiller R, Mathis D, Stoddard R, Kersh GJ, Dickerson B, Gelatt T (2014) Brucella placentitis and seroprevalence in northern fur seals (Callorhinus ursinus) of the Pribilof Islands, Alaska. J Vet Diagn Invest 26: 507-512

Ewalt DR, Payeur JP, Martin BM, Miller WG (1994) Characteristics of a Brucella species from a bottlenose dolphin (Tursiops truncatus). J Vet Diagn Invest 6:448-452

Foster G, Osterman BS, Godfroid J, Jacques I, Cloeckaert A (2007) Brucella ceti sp. nov. and Brucella pinnipedialis sp. nov. for Brucella strains with cetaceans and seals as their preferred hosts. Int J Syst Evol Microbiol 57: 2688-2693

Gardiner CH, Poynton SL (2006) An atlas of metazoan parasites in animal tissues. Armed Forces Institute of Pathology, Washington, DC

*Garner MM, Lambourn DM, Jeffries SJ, Hall PB and others (1997) Evidence of Brucella infection in Parafilaroides lungworms in a Pacific harbor seal (Phoca vitulina richardsi). J Vet Diagn Invest 9:298-303

González L, Patterson IA, Reid RJ, Foster G and others (2002) Chronic meningoencephalitis associated with 
Brucella sp. infection in live-stranded striped dolphins (Stenella coeruleoalba). J Comp Pathol 126:147-152

González-Barrientos R, Morales JA, Hernández-Mora G, Barquero-Calvo E, Guzmán-Verri C, Chaves-Olarte E, Moreno E (2010) Pathology of striped dolphins (Stenella coeruleoalba) infected with Brucella ceti. J Comp Pathol 142:347-352

*Guzmán-Verri C, González-Barrientos R, Hernández-Mora G, Morales JA, Baquero-Calvo E, Chaves-Olarte E, Moreno E (2012) Brucella ceti and brucellosis in cetaceans. Front Cell Infect Microbiol 2:3

* Hernández-Mora G, Gonzáles-Barrientos R, Morales JA, Chaves-Olarte E and others (2008) Neurobrucellosis in stranded dolphins, Costa Rica. Emerg Infect Dis 14: 1430-1433

Hernández-Mora G, Palacios-Alfaro JD, González-Barrientes R (2013) Wildlife reservoirs of brucellosis: Brucella in aquatic environments. Rev Sci Tech Off Int Epizoot 32:89-103

*Hoover-Miller A, Dunn JL, Field CL, Blundell G, Atkinson S (2017) Seroprevalence of Brucella antibodies in harbor seals in Alaska, USA, with age, regional, and reproductive comparisons. Dis Aquat Org 126:1-12

Jauniaux TP, Brenez C, Fretin D, Godfroid J and others (2010) Brucella ceti infection in harbor porpoise (Phocoena phocoena). Emerg Infect Dis 16:1966-1968

Kershaw JL, Stubberfield EJ, Foster G, Brownlow A, Hall AJ, Perrett LL (2017) Exposure of harbour seals Phoca vitulina to Brucella in declining populations across Scotland. Dis Aquat Org 126:13-23

Kramer LH, Passeri B, Corona S, Simoncini L, Casiraghi M (2003) Immunohistochemical/immunogold detection and distribution of the endosymbiont Wolbachia of Dirofilaria immitis and Brugia pahangi using a polyclonal antiserum raised against WSP (Wolbachia surface protein). Parasitol Res 89:381-386

Kroese MV, Beckers L, Bisselink YJWM, Brasseur S and others (2018) Brucella pinnipedialis in grey seals (Halichoerus grypus) and harbor seals (Phoca vitulina) in the Netherlands. J Wildl Dis 54:439-449

* Lambourn DM, Garner M, Ewalt D, Raverty S and others (2013) Brucella pinnipedialis infections in Pacific harbor seals (Phoca vitulina richardsi) from Washington State, USA. J Wildl Dis 49:802-815

*Larsen AK, Nymo IH, Boysen P, Tryland M, Godfroid J (2013) Entry and elimination of marine mammal Brucella spp. by hooded seal (Cystophora cristata) alveolar macrophages in vitro. PLOS ONE 8:e70186

Larsen AK, Godfroid M, Nymo IH (2016) Brucella pinnipedialis in hooded seal (Cystophora cristata) primary epithelial cells. Acta Vet Scand 58:9

Lehnert K, von Samson-Himmelstjerna G, Schaudien D, Bleidorn C, Wohlsein P, Siebert U (2010) Transmission of lungworms of harbour porpoises and harbour seals: Molecular tools determine potential vertebrate intermediate hosts. Int J Parasitol 40:845-853

Maio E, Begeman L, Bisselink Y, van Tulden P and others (2014) Identification and typing of Brucella spp. in stranded harbour porpoises (Phocoena phocoena) on the Dutch coast. Vet Microbiol 173:118-124

* Maratea J, Ewalt DR, Frasca S Jr, Dunn JL and others (2003) Evidence of Brucella sp. infection in marine mammals stranded along the coast of southern New England. J Zoo Wildl Med 34:256-261

McDonald WL, Jamaludin R, Mackereth G, Hansen M and others (2006) Characterization of a Brucella sp. strain as a marine-mammal type despite isolation from a patient with spinal osteomyelitis in New Zealand. J Clin Microbiol 44:4363-4370

Measures LN (2001) Lungworms of marine mammals. In: Samuel WM, Pybus MJ, Kocan AA (eds) Parasitic diseases of wild mammals, $2^{\text {nd }}$ edn. Iowa State University Press, Ames, IA, p 279-300

Miller WG, Adams LG, Ficht TA, Cheville NF and others (1999) Brucella-induced abortions and infection in bottlenose dolphins (Tursiops truncatus). J Zoo Wildl Med 30:100-110

* Morales GA, Helmboldt CF (1971) Verminous pneumonia in the California sea lion (Zalophus californicus). J Wildl Dis 7:22-27

Muelbert MMC, Bowen WD (1993) Duration of lactation and postweaning changes in mass and body composition of harbour seal, Phoca vitulina, pups. Can J Zool 71: 1405-1414

Nymo IH, Tryland M, Godfroid J (2011) A review of Brucella infection in marine mammals, with special emphasis on Brucella pinnipedialis in the hooded seal (Cystophora cristata). Vet Res 42:93

Nymo IH, Tryland M, Frie AK, Haug T, Foster G, Rødven R, Godfroid J (2013) Age-dependent prevalence of antiBrucella antibodies in hooded seals Cystophora cristata. Dis Aquat Org 106:187-196

*Nymo IH, Seppola M, Dahouk SA, Bakkemo KR, Jiménez de Bagüés MP, Godfroid J, Larsen AK (2016) Experimental challenge of Atlantic cod (Gadus morhua) with a Brucella pinnipedialis strain from hooded seal (Cystophora cristata). PLOS ONE 11:e0159272

Osinga N (2015) Comparative biology of common and grey seals along the Dutch coast: stranding, disease, rehabilitation and conservation. $\mathrm{PhD}$ dissertation, Leiden University

* Perrett LL, Brew SD, Stack JA, MacMillan AP, Bashiruden JB (2004a) Experimental assessment of the pathogenicity of Brucella strains from marine mammals for pregnant sheep. Small Rumin Res 51:221-228

* Perrett LL, Dawson CE, Davison N, Quinney S (2004b) Brucella infection of lung worms from a harbour porpoise. Vet Rec 154:800

Rhyan JC (2000) Brucellosis in terrestrial wildlife and marine mammals. In: Brown C, Bolin C (eds) Emerging diseases of animals. ASM Press, Washington DC, p 164-184

* Rhyan JC, Gidlewski T, Ewalt DR, Hennager SG, Lambourne DM, Olsen SC (2001) Seroconversion and abortion in cattle experimentally infected with Brucella sp. isolated from a Pacific harbor seal (Phoca vitulina richardsi). J Vet Diagn Invest 13:379-382

* Ross HM, Foster G, Reid RJ, Jahans KL, MacMillan AP (1994) Brucella species infection in sea-mammals. Vet Rec 134:359

* Sohn AH, Probert WS, Glaser CA, Gupta N and others (2003) Human neurobrucellosis with intracerebral granuloma caused by a marine mammal Brucella spp. Emerg Infect Dis 9:485-488

Ulrich SA, Lehnert K, Rubio-Garcia A, Sanchez-Contreras J, Strube C, Siebert U (2016) Lungworm seroprevalence in free-ranging harbour seals and molecular characterisation of marine mammal MSP. Int J Parasitol Parasites Wildl 5:48-55

Whatmore AM, Dawson V, Muchowski J, Perrett LL and others (2017) Characterisation of North American Brucella isolates from marine mammals. PLOS ONE 12: e0184758 